\title{
ANALISIS KEBUTUHAN PENGEMBANGAN APLIKASI MEDIA PROMOSI WISATA BERBASIS ANDROID DI KABUPATEN KUBU RAYA
}

\author{
Isnania Lestari $^{1}$, Erni Fatmawati ${ }^{1}$, Muhammad Ramadhani ${ }^{1}$ \\ ${ }^{1}$ IKIP PGRI Pontianak, Program Studi Pendidikan \\ Teknologi Informasi dan Komputer, Pontianak
}

Email korespondensi: isnanialestari@gmail.com

\begin{abstract}
Abstrak
Tujuan penelitian ini untuk mengetahui pengetahuan masyarakat tentang destinasi wisata yang berada di Provinsi Kalimantan Barat Khususnya di Kabupaten Kubu Raya. Data yang diperoleh akan di olah untuk dijadikan sebagai data awal untuk pengembangan aplikasi media promosi wisata berbasis android di Kabupaten Kubu Raya. Penelitian ini menggunakan metode deskriptif dengan bentuk penelitian survei. Populasi yang digunakan adalah populasi infinite, dengan Teknik random sampling dan alat pengumpulan datanya adalah angket. Berdasarkan hasil analisis data, 75\% responden berasal dari mahasiswa, rentang usia 17 - 30 tahun. Daerah asal responden hampir merata berasal dari seluruh wilayah kota dan kabupaten yang terdapat di provinsi Kalimantan Barat. Persentase pengetahuan responden mengenai destinasi wisata yang terdapat di Kabupaten Kubu Raya adalah 39\%. 88,9\% responden menyatakan perlu dibuatkan Aplikasi yang membantu masyarakat untuk mengetahui informasi mengenai destinasi wisata yang berada di Kabupaten Kubu Raya. Berdasarkan hasil analisis data tersebut, maka dapat disimpulkan bahwa pengembangan aplikasi berbasis android dibutuhkan oleh masyarakat agar dapat menerima informasi dengan cepat dan tepat khususnya mengenai wisata yang terdapat di Kabupaten Kubu Raya.
\end{abstract}

Kata kunci: Pengembangan, wisata, android

\section{PENDAHULUAN}

Banyak sektor yang memberikan
kontribusi terhadap perkembangan
ekonomi di Indonesia. Pariwisata
merupakan multiplier effect terbesar dan
merupakan salah satu sektor unggulan yang
berperan meningkatkan perekonomian
nasional (Arfanius \& Hafid, 2017).
Pariwisata dapat meningkatkan pendapatan devisa yang diterima oleh negara, meningkatkan pendapatan daerah, menjadi sumber pengembang wilayah dan juga dapat menarik investor serta menciptakan lapangan kerja dan pengembangan usaha baru.

Sektor yang dapat menarik sektor lain di suatu negara untuk berkembang adalah sektor wisata, karena produk yang dihasilkan diperlukan untuk menunjang industry pariwisata tersebut (Hanum \& Saifudin, 2019). Terdapat empat kriteria dalam pariwisata, yakni perjalanan dilakukan di luar tempat tinggal, tujuan perjalanan adalah bersenang-senang, uang yang digunakan berasal dari tempat wisatawan tinggal dan perjalanan dilakukan minimal 24 jam (Primadany, 2013). Selanjutnya, banyak jenis pariwisata yang terdapat di Indonesia yang sudah terkenal baik untuk wisatawan lokal maupun internasional. Suryadana \& Vanny (2015) menyebutkan bahwa pariwisata dibagi ke dalam 2 jenis, yakni wisata alam yang berarti memanfaatkan keindahan alam sebagai objek wisata dan wisata social budaya yang melibatkan peninggalan sejarah ataupun monument yang dijadikan objek wisata. Destinasi wisata yang berada di Indonesia dan memiliki daya tarik tinggi untuk wisatawan nasional dan mancanegara salah satunya adalah Bali. Bali terkenal akan kekayaan alam dan budaya yang sangat indah sehingga menarik banyak wisatawan untuk datang. Selain Bali, masih banyak tujuan wisata di Indonesia yang memiliki potensi yang tinggi jika dikelola secara baik.

Provinsi Kalimantan Barat juga memiliki banyak tempat pariwisata yang sangat menarik untuk dikunjungi baik itu di daerah 
perkotaan maupun di kecamatan ataupun kabupaten. Berdasarkan data yang didapat dari Dinas Kepemudaan Olahraga Dan Pariwisata Kabupaten Kubu Raya, untuk daerah Kabupaten Kubu Raya memiliki lima destinasi wisata utama yang bisa dikunjungi oleh wisatawan. Destinasi wisata tersebut terdiri dari wisata alam dan ekowisata. Namun tidak semua destinasi wisata tersebut memiliki akses yang baik untuk dilalui oleh kendaraan, baik kendaraan roda 2 ataupun 4 .

Destinasi wisata yang berada di Kabupaten Kubu Raya antara lain:

1. Ekowisata Tugu Telok Berdiri

Kawasan ekowisata Tugu Telok Berdiri merupakan kawasan yang menawarkan pemandangan indah dan juga track hutan mangrove dengan pemandangan pesisir laut natuna. Kawasan ini memiliki tower yang menjulang tinggi dengan kokoh. Selain itu Kawasan ini memiliki pemandangan yang eksotis.

2. Danau Hoce

Danau Hoce adalah danau buatan yang diperuntukkan sebagai sarana rekreasi dan olahraga baik untuk masyarakat sekitar dan juga umum. Danau ini terletak di Jalan Raya Kuala Dua Desa Kuala Dua Kecamatan Sungai raya

3. Wisata Hutan Albasia

Wisata Hutan Albasia merupakan hutan wisata yang memiliki konsep hangout bersama alam. Hutan ini ditumbuhi oleh pohon Albasia milik perusahaan PT. Alas Kusuma. Kawasan ini cocok untuk dijadikan tempat camping dan hammocking.

4. Ekowisata Beteng Batang

Kawasan wisata Beteng Batang berada di Desa Dabung. Desa ini terletak di Kawasan hutan lindung mangrove. Ekowisata tersebut memiliki track mangrove sepanjang 1,2 km dan juga memiliki pantai pasir hitam yang eksotis. Kawan wisata ini memiliki potensi kuliner yang tinngi, karena berada di pesisir pantai.

5. Kapal Muare Kakap

Muare Sungai Kakap merupakan salah satu muara yang berada di Kabupaten
Kubu Raya. Banyak tempat menarik yang dapat dikunjungi dengan menggunakan kapal Muare Kakap.

Walau banyak destinasi wisata di Kabupaten Kubu Raya, namun banyak masyarakat khususnya masyarakat Kalimantan Barat yang belum mengetahui tempat tersebut. Oleh sebab itu, dibutuhkan sebuah analisis untuk mengetahui sejauh mana masyarakat mengetahui mengenai tempat tersebut. Hasil analisis tersebut nantinya digunakan sebagai analisis kebutuhan untuk pembuatan teknologi yang dibutuhkan masyarakat.

Pemanfaatan teknologi dalam mengolah dan menyebarkan informasi dapat digunakan dalam berbagai bidang, termasuk pariwisata. Penyebaran informasi ini diperlukan supaya masyarakat mengetahui mengenai destinasi wisata khususnya yang berada di Kabupaten Kubu Raya. Informasi ini juga dapat digunakan sebagai salah satu media promosi untuk menarik jumlah wisatawan agar berkunjung ke destinasi wisata yang ada.

Salah satu teknologi yang paling mudah dan banyak digunakan oleh masyarakat saat ini adalah Smartphone Android. (Siddik \& Nasution (2018) menjelaskan bahwa sistem Operasi Android merupakan pangsa pasar terbesar saat ini. Hal ini juga diperkuat dengan data yang menjelaskan bahwa pengguna android pada tahun 2020 mencapai $70,1 \%$ dari total jumlah populasi penduduk Indonesia (Pusparisa, 2020). Dan diperkirakan penggunaan android akan meningkat setiap tahunnya.

Android merupakan sistem operasi yang digunakan di mobile device seperti smartphone (Wahadoyo, 2013). Pengoperasian smartphone android tidak begitu sulit, maka dari itu banyak masyarakat yang menggunakannya. Hal ini diperjelas oleh Zulkiplih et al. (2020) bahwa secara efisiensi android memiliki kelebihan dalam menyajikan informasi yaitu kemudahan dalam penggunaannya dan minimum biaya karena bersifat open source. Selanjutnya, Anton dalam (Ependi et al., 2020) menjelaskan bahwa pengguna mobile device dan internet tertinggi berada pada usia 25 
sampai 35 tahun, dan wisatawan yang sering melakukan perjalanan berada pada rentang usia tersebut. Selain itu, Basith \& Kurniadi (2017) menjelaskan bahwa dengan memanfaatkan aplikasi berbasis android, dapat membantu memperluas jangkauan kepada masyarakat dalam menyampaikan informasi khususnya mengenai pariwisata. 'Berdasarkan data dan pernyataan tersebut, terlihat bahwa pengembangan aplikasi berbasis android memiliki potensi yang tinggi untuk digunakan dalam penyebaran informasi yang dapat digunakan sebagai salah satu media promosi khususnya pariwisata.

\section{METODOLOGI}

Penelitian ini menggunakan metode deskriptif. Metode ini digunakan untuk mengetahui sejauh mana pengetahuan masyarakat Kalimantan Barat mengenai destinasi wisata khususnya yang berada di Kabupaten Kubu Raya. Bentuk penelitian yang digunakan dalam penelitian ini adalah survei (survey studies). Populasi dalam penelitian ini adalah populasi infinite. Karena jumlah populasi yang tidak dapat diketahui secara pasti. Dengan teknik sampling yang digunakan adalah Random Sampling. Jumlah responden yang didapat dalam penelitian ini adalah sebanyak 117.

Pengumpulan data yang digunakan dalam penelitian ini adalah teknik komunikasi tidak langsung, dengan alat pengumpulan data berupa angket. Angket tersebut adalah angket tertutup dengan 2 pilihan jawaban dan juga angket terbuka yang memungkinkan responden untuk mengisi pertanyaan sesuai dengan pengetahuan responden. Angket tersebut berisi pertanyaan mengenai pengetahuan responden terhadap beberapa destinasi wisata yang ada di Kabupaten Kubu Raya. Selain itu, terdapat pertanyaan mengenai kebutuhan akan media sumber informasi yang bisa digunakan sebagai media promosi wisata kepada masyarakat. Hal tersebut perlu diketahui agar peneliti dapat mengetahui sejauh mana kebutuhan masyarakat akan aplikasi media promosi berbasis android ini.

Angket tersebut menghasilkan dua jenis data, yakni data kualitatif dan kuantitatif. Data kualitatif disajikan dalam bentuk teks naratif. Selain itu disajikan juga dalam bentuk matriks, gambar dan bagan untuk memperjelas hasil data. Selanjutnya data kuantitatif disajikan dalam bentuk angka persentase. Yang selanjutnya dideskripsikan berdasarkan kategori skor.

\section{HASIL DAN PEMBAHASAN}

Hasil

Analisis kebutuhan yang dilakukan adalah untuk mengetahui sejauh mana pengetahuan masyarakat Kalimantan Barat mengenai destinasi wisata yang terletak di Kabupaten Kubu Raya. Hasil dari pengolahan data analisis kebutuhan ini selanjutnya akan digunakan sebagai data awal untuk melakukan pengembangan Aplikasi berbasis Android yang berfungsi untuk media promosi pariwisata khususnya yang berada di Kabupaten Kubu Raya. Penyajian hasil pengolahan data dilakukan dalam bentuk skor, persentase dan juga deskripsi hasil analisis data.

Responden dalam penelitian ini adalah berjumlah 117 orang. Responden dibagi menjadi beberapa golongan pekerjaan, usia dan juga daerah asal. Penggolongan tersebut dapat dilihat dalam tabel 1 berikut ini.

Tabel 1. Kategori Responden Berdasarkan Penggolongan Pekerjaan, Usia, dan Daerah Asal

\begin{tabular}{|c|c|c|c|}
\hline No & Jenis & Uraian & $\begin{array}{c}\text { Jumlah } \\
\text { Responden }\end{array}$ \\
\hline \multirow[t]{6}{*}{1} & \multirow{6}{*}{ Pekerjaan } & $\begin{array}{ll}\text { Ibu } & \text { Rumah } \\
\text { Tangga } & \\
\end{array}$ & 8 \\
\hline & & Pegawai & 6 \\
\hline & & Wiraswasta & 6 \\
\hline & & $\begin{array}{l}\text { Pelajar/ } \\
\text { Mahasiswa }\end{array}$ & 88 \\
\hline & & Lainnya & 9 \\
\hline & & Total & 117 \\
\hline \multirow[t]{2}{*}{2} & \multirow{2}{*}{ Usia } & $\begin{array}{lll}\begin{array}{l}\text { Kurang } \\
\text { Tahun }\end{array} & 17 \\
\end{array}$ & 0 \\
\hline & & $17-30$ & 94 \\
\hline
\end{tabular}




\begin{tabular}{|c|c|c|c|}
\hline No & Jenis & Uraian & $\begin{array}{c}\text { Jumlah } \\
\text { Responden }\end{array}$ \\
\hline & & Di atas 30 Tahun & 23 \\
\hline & & Total & 117 \\
\hline \multirow[t]{14}{*}{3} & \multirow{14}{*}{ Daerah Asal } & $\begin{array}{l}\text { Kabupaten } \\
\text { Bengkayang }\end{array}$ & 5 \\
\hline & & $\begin{array}{l}\text { Kabupaten } \\
\text { Kapuas Hulu }\end{array}$ & 7 \\
\hline & & $\begin{array}{l}\text { Kabupaten } \\
\text { Ketapang }\end{array}$ & 14 \\
\hline & & $\begin{array}{l}\text { Kabupaten } \\
\text { Kubu Raya }\end{array}$ & 16 \\
\hline & & $\begin{array}{l}\text { Kabupaten } \\
\text { Landak }\end{array}$ & 8 \\
\hline & & $\begin{array}{l}\text { Kabupaten } \\
\text { Melawi }\end{array}$ & 4 \\
\hline & & $\begin{array}{l}\text { Kabupaten } \\
\text { Mempawah }\end{array}$ & 4 \\
\hline & & $\begin{array}{l}\text { Kabupaten } \\
\text { Sambas }\end{array}$ & 3 \\
\hline & & $\begin{array}{l}\text { Kabupaten } \\
\text { Sanggau }\end{array}$ & 10 \\
\hline & & $\begin{array}{l}\text { Kabupaten } \\
\text { Sekadau }\end{array}$ & 3 \\
\hline & & $\begin{array}{l}\text { Kabupaten } \\
\text { Sintang }\end{array}$ & 7 \\
\hline & & Kota Pontianak & 33 \\
\hline & & $\begin{array}{l}\text { Kota } \\
\text { Singkawang }\end{array}$ & 3 \\
\hline & & Total & 117 \\
\hline
\end{tabular}

Berdasarkan tabel tersebut, dapat diketahui bahwa responden paling banyak berasal dari Mahasiswa. Persentase mahasiswa adalah sebanyak $75 \%$. Sedangkan untuk Ibu rumah tangga adalah 7\%, selanjutnya $5 \%$ Wiraswasta, $5 \%$ pegawai dan $8 \%$ adalah pekerjaan yang tidak di deskripsikan dalam angket atau lainnya. Persentase tersebut dapat dilihat dalam diagram gambar 1 berikut.

\section{Pekerjaan Responden}

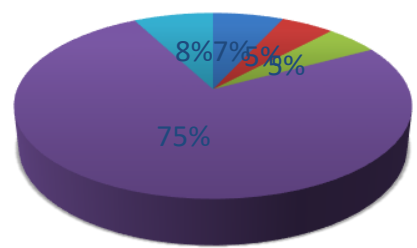

- Ibu Rumah Tangga $\mathbf{\text { Pegawai }}$

wiraswasta

- Pelajar/Mahasiswa Lainnya

Gambar 1: Diagram Persentase Pekerjaan Responden
Selanjutnya rentang usia terbanyak untuk responden adalah berusia $17-30$ tahun. Usia tersebut mencakup $80 \%$ dari keseluruhan responden. Selanjutnya 20\% berasal dari rentang usia diatas 30 tahun. Persentase data tersebut dapat dilihat dalam diagram gambar 2 berikut ini.

\section{Usia Responden}

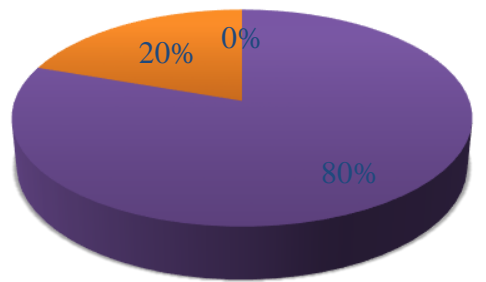

— Kurang dr 17 Tahun $\quad$ 17-30 Diatas 30 Tahun
Gambar 2: Diagram Persentase Usia Responden

Untuk daerah asal hampir merata, yakni berasal dari semua Kota dan/atau Kabupaten yang terdapat di Provinsi Kalimantan Barat. Namun responden paling banyak berasal dari Kota Pontianak yakni sebanyak 33 responden dan Kabupaten Kubu Raya sebanyak 6 responden. Persentase data daerah asal responden dapat dilihat dalam diagram gambar 3 berikut.

\section{Daerah Asal Responden}

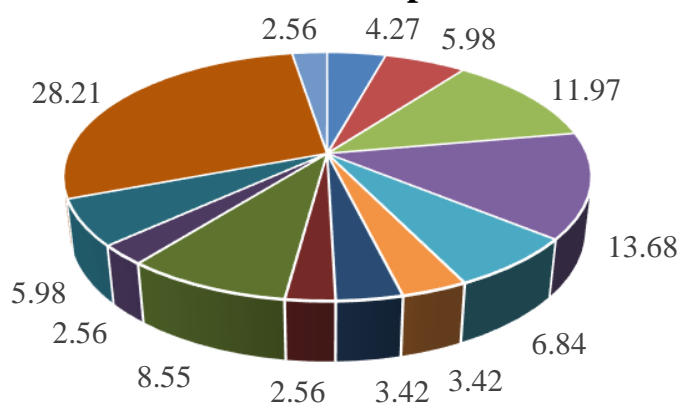

- Bengkayang

- Kapuas Hulu

- Kabupaten Ketapang

- Kabupaten Landak

- Kabupaten Mempawah

- Kabupaten Sanggau

- Kabupaten Kubu Raya

- Kabupaten Melawi

- Kabupaten Sambas

- Kabupaten Sintang

- Kota Pontianak

Gambar 3: Diagram Persentase Daerah Asal Responden 
Selanjutnya, hasil analisis data tentang pengetahuan responden mengenai destinasi wisata yang berada di Kabupaten Kubu Raya, dapat dilihat dalam tabel 1 berikut.

Tabel 2: Pengetahuan Responden terhadap Lokasi Wisata

\begin{tabular}{|c|c|c|c|c|c|c|c|c|c|c|c|}
\hline \multirow{3}{*}{$\begin{array}{l}\mathbf{N} \\
\mathbf{0}\end{array}$} & \multirow{3}{*}{ Uraian } & \multicolumn{10}{|c|}{ Nama Destinasi wisata } \\
\hline & & \multicolumn{2}{|c|}{$\begin{array}{c}\text { Telok } \\
\text { Berdi } \\
\text { ri }\end{array}$} & \multicolumn{2}{|c|}{$\begin{array}{c}\text { Dana } \\
\text { u } \\
\text { Hose }\end{array}$} & \multicolumn{2}{|c|}{$\begin{array}{c}\text { Huta } \\
\text { n } \\
\text { Albas } \\
\text { ia }\end{array}$} & \multicolumn{2}{|c|}{$\begin{array}{l}\text { Beten } \\
\text { g } \\
\text { Batan } \\
\text { g }\end{array}$} & \multicolumn{2}{|c|}{$\begin{array}{c}\text { Kapal } \\
\text { Muar } \\
\text { e } \\
\text { Kaka } \\
\text { p } \\
\end{array}$} \\
\hline & & $\mathbf{S}$ & $\%$ & $\mathbf{S}$ & $\%$ & $\mathbf{S}$ & $\%$ & $\mathbf{S}$ & $\%$ & $\mathbf{S}$ & $\%$ \\
\hline 1 & $\begin{array}{l}\text { Mengeta } \\
\text { hui }\end{array}$ & 3 & 3 & 4 & 3 & 5 & 4 & 2 & 2 & 7 & 6 \\
\hline & $\begin{array}{l}\text { Destinas } \\
\text { i wisata }\end{array}$ & 5 & 0 & 2 & 6 & 6 & 8 & 5 & 1 & 0 & 0 \\
\hline 2 & $\begin{array}{l}\text { Fasilitas } \\
\text { Destinas } \\
\mathrm{i} \quad \text { wisata }\end{array}$ & 1 & 4 & 1 & 2 & 2 & 4 & & 3 & 2 & 2 \\
\hline 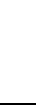 & $\begin{array}{l}\text { Belum } \\
\text { Memada } \\
\text { i }\end{array}$ & 7 & 9 & 2 & 9 & 6 & 6 & 9 & 6 & 0 & 9 \\
\hline 3 & $\begin{array}{l}\text { Menggu } \\
\text { nakan } \\
\text { Transpor }\end{array}$ & & & & & & & & & & \\
\hline & $\begin{array}{l}\text { tasi } \\
\text { Umum }\end{array}$ & 1 & 2 & 1 & 4 & $\begin{array}{l}2 \\
5\end{array}$ & $\begin{array}{l}4 \\
5\end{array}$ & $\begin{array}{l}1 \\
4\end{array}$ & 5 & $\begin{array}{l}3 \\
8\end{array}$ & $\begin{array}{l}5 \\
4\end{array}$ \\
\hline & $\begin{array}{l}\text { Umum } \\
\text { Ke } \\
\text { Lokasi } \\
\text { Wisata }\end{array}$ & 0 & 9 & 7 & 0 & 5 & & 4 & & 8 & \\
\hline 4 & $\begin{array}{l}\text { Akses } \\
\text { Ke } \\
\text { Destinas }\end{array}$ & 2 & 5 & 3 & 8 & 3 & 6 & 1 & 6 & 5 & 8 \\
\hline & $\begin{array}{l}\text { i wisata } \\
\text { Sudah } \\
\text { Baik }\end{array}$ & 0 & 7 & 4 & 1 & 5 & 2 & 7 & 8 & 6 & 0 \\
\hline
\end{tabular}

Berdasarkan tabel 2 tersebut, diketahui bahwa terdapat banyak responden yang belum mengetahui destinasi wisata yang berada di Kabupaten Kubu Raya. Hal tersebut dapat dilihat dari rata - rata persentase responden yang menjawab kurang dari $50 \%$ yakni hanya $39 \%$ untuk pertanyaan mengenai pengetahuan destinasi wisata yang ada. Selanjutnya responden juga belum banyak mengetahui tentang fasilitas yang terdapat di tempat tersebut. Terlihat dari rata- rata persentasenya yakni $37.8 \%$. selain itu ratarata persentase responden mengenai transportasi yang digunakan menuju lokasi wisata pun masih rendah, yakni $44.8 \%$. dan yang terakhir adalah rata - rata persentase responden mengenai akses ke destinasi wisata yang telah disebutkan adalah $69.8 \%$.

Hal tersebut menggambarkan bahwa banyak masyarakat yang belum mengetahui destinasi wisata yang dapat dikunjungi di Kabupaten Kubu Raya. Dan juga masyarakat belum mengetahui fasilitas, dan juga akses untuk menuju destinasi wisata tersebut. Hal inilah yang bisa dijadikan data awal bagi peneliti untuk membuat sebuah aplikasi berbasis android sebagai salah satu sarana untuk dijadikan media promosi destinasi wisata tersebut agar masyarakat lebih tahu dan tertarik untuk datang berwisata ke tempat - tempat tersebut.

Selain mengumpulkan data tentang pengetahuan responden mengenai destinasi wisata yang berada di Kabupaten Kubu Raya, peneliti juga menanyakan mengenai kebutuhan responden mengenai kebutuhan aplikasi untuk media informasi ataupun promosi untuk destinasi - destinasi wisata tersebut. Sebanyak $88,9 \%$ responden menjawab perlu dibuatkan aplikasi. Hal ini berkaitan dengan kemudahan informasi yang bisa didapat oleh masyarakat mengenai destinasi wisata yang dapat dikunjungi oleh wisatawan baik yg berasal dari Kabupaten Kubu Raya ataupun dari daerah lain.

Selain kelima destinasi wisata yang telah disebutkan sebelumnya, responden juga menyebutkan beberapa destinasi wisata yang bisa dijadikan destinasi wisata, yakni:

1. Pantai Indah Kakap

2. Wisata Balek Kampong

3. Bukit Ambawang

4. Paradise Waterpark

5. Pantai Selakseh Batu Ampar

6. Saung Nila

7. Air Terjun Gunung Ambawang

8. Muara Kakap

9. Hutan Mangrove

\section{Pembahasan}

Destinasi wisata merupakan salah satu tujuan yang sering dicari masyarakat untuk melakukan rekreasi. Tujuannya adalah untuk mencari suasana yang nyaman untuk refreshing ataupun bersenang-senang dengan teman ataupun keluarga. Pemilihan destinasi wisata juga harus disesuaikan dengan kebutuhan wisatawan. Di provinsi Kalimantan Barat, khususnya di Kabupaten Kubu Raya, terdapat 5 destinasi wisata yang dapat di kunjungi oleh masyarakat. Baik itu lokal ataupun masyarakat luar. Destinasi 
wisata tersebut adalah Teluk Berdiri, Danau Hoce, Hutan Albasia, Beteng Batang dan Kapal Muare Kakap. Tempat - destinasi wisata tersebut menawarkan keindahan pemandangan alam yang indah. Mulai dari hutan bakau, danau buatan yang indah, fasilitas kapal yang dapat menyebrangi sungai, dan masih banyak lagi.

Jika destinasi wisata tersebut banyak dikunjungi wisatawan, maka akan membantu ekonomi para pelaku wisata yang ada di daerah tersebut. Namun sayang, masyarakat banyak yang belum mengetahui mengenai destinasi wisata tersebut. Hal ini dapat dilihat dari persentase jawaban responden yakni hanya $39 \%$ yang mengetahui tempat destinasi wisata tersebut. Hal ini dikarenakan kurangnya promosi mengenai tempat destinasi wisata tersebut. Maka dari itu masyarakat banyak yang belum mengetahui tempat tersebut.

Berdasarkan data yang telah diperoleh dari Dinas Kepemudaan Olahraga Dan Pariwisata, lima Destinasi wisata tersebut memiliki potensi yang sangat bagus, baik untuk destinasi wisata maupun tempat untuk mengembangkan perekonomian. Karena tempat - tempat tersebut memiliki pemandangan yang sangat indah dan juga tempat rekreasi yang sangat menarik. Namun yang sangat disayangkan adalah akses jalan yang kurang memadai. Jadi hal ini yang menyebabkan masyarakat enggan mengunjungi destinasi wisata tersebut. Dan hal ini berimbas kepada jumlah pengunjung yang sedikit sehingga destinasi wisata tersebut kurang berkembang.

Berdasarkan hasil analisis data, 88,9\% responden mengatakan bahwa perlu dibuatkan aplikasi yang dapat mendukung masyarakat untuk lebih mudah dalam mengetahui seluruh informasi mengenai tempat - destinasi wisata khususnya yang berada di Kabupaten Kubu Raya. Data tersebut merupakan data awal yang akan digunakan sebagai dasar dalam pengembangan Aplikasi Media Promosi Berbasis Android. Aplikasi android merupakan aplikasi yang paling mudah untuk digunakan oleh masyarakat atau wisatawan.
Karena sebagian besar masyarakat telah menggunakan smartphone android, maka aplikasi yang akan dibuat akan mudah sampai kepada masyarakat.

Pengembangan aplikasi ini diharapkan dapat membantu para penggiat wisata untuk lebih mudah dalam mempromosikan destinasi wisata khususnya yang terletak di Kabupaten Kubu Raya. Selain itu juga, aplikasi ini dapat digunakan oleh wisatawan sebagai media informasi supaya wisatawan dapat mengetahui secara detail mengenai destinasi wisata yang akan dan bisa dikunjungi.

\section{KESIMPULAN}

Pariwisata yang berada di Kabupaten Kubu Raya memiliki potensi yang tinggi jika dikelola dan dikembangkan dengan maksimal. Sektor pariwisata merupakan salah satu sektor potensial yang dapat membantu perekonomian baik untuk masyarakat sekitar maupun untuk pemerintah daerah. Berdasarkan hasil analisis data, masih banyak masyarakat yang belum mengetahui mengenai destinasi wisata yang berada di Kabupaten Kubu Raya, yakni hanya 39\% dari keseluruhan responden. Berdasarkan data tersebut, peneliti akan membuat sebuah aplikasi berbasis android yang nantinya akan dijadikan media promosi dan juga penyebaran informasi mengenai destinasi wisata yang berada di Kabupaten Kubu Raya. Hal ini diharapkan dapat membantu para pelaku wisata untuk mengembangkan sektor wisata khususnya yang berada di Kabupaten Kubu Raya.

\section{UCAPAN TERIMA KASIH}

Ucapan terima kasih kami sampaikan kepada IKIP PGRI Pontianak melalui Lembaga Penelitian dan Pengabdian Kepada Masyarakat (LPPM) yang telah mendanai program penelitian ini.

\section{DAFTAR PUSTAKA}


Arfanius, S., \& Hafid, Y. P. (2017). Pengembangan Aplikasi WEB GIS Pariwisata Backpacker. Yogyakarta: Deepublish.

Basith, G. H., \& Kurniadi, D. (2017). Perancangan Sistem Informasi Pemetaan Pariwisata Garut Berbasis Geografic Information System dan Android. Jurnal Algoritma Sekolah Tinggi Teknologi Garut II., 14(1), 2631.

https://doi.org/10.33364/algoritma/v. 14- 1.26

Ependi, U., Panjaitan, F., \& Syakti, F. (2020). Pengembangan Aplikasi Mobile Travel Guide pada Provinsi Sumatera Selatan. Jurnal Teknologi Informasi Dan Ilmu Komputer, 7(3), 607. https://doi.org/10.25126/jtiik.202073 2107

Hanum, W. S., \& Saifudin, A. (2019). Rancang Bangun Aplikasi Panduan Pariwisata di Kabupaten Banyuwangi Mobile Berbasis Android. Jurnal Teknologi Sistem Informasi Dan Aplikasi, 2(2), 59. https://doi.org/10.32493/jtsi.v2i2.279 8

Pusparisa, Y. (2020). Pengguna Smartphone diperkirakan Mencapai 89\% Populasi pada 2025. Databoks.Katadata.Co.Id. https://databoks.katadata.co.id/datapu blish/2020/09/15/penggunasmartphone-diperkirakan-mencapai89-populasi-pada-2025

Primadany, S. R. (2013). Analisis Strategi Pengembangan Pariwisata Daerah (Studi pada Dinas Kebudayaan dan Pariwisata Daerah Kabupaten Nganjuk). Jurnal Administrasi Publik, 1(4), 135-143.

Siddik, M., \& Nasution, A. (2018). Perancangan Aplikasi Push Notification Berbasis Android. Jurteksi, $\quad 4(2), \quad$ 149-154. https://doi.org/10.33330/jurteksi.v4i2 .56

Suryadana, M. L., \& Vanny, O. (2015). Pengantar Pemasaran Pariwisata. Bandung: Alfabeta.

Wahadoyo, A. (2013). Android 4 untuk pengguna pemula tablet \& handphone. Mediakita

Zulkiplih, Syahrul, \& Parenreng, J. M. (2020). Pengembangan Aplikasi Pariwisata Sulawesi Barat Berbasis Android. Journal of Embedded Systems, Security and Intelligent Systems, $\quad 1(1), \quad 48-56$. https://ojs.unm.ac.id/JESSI/article/vi ew/1 
Bidang Lingkungan Binaan dan Rekayasa 